\title{
"Argumentar é bem a fase deles...": crenças de professores sobre a argumentação em sala de aula
}

\author{
Dorotea Frank Kersch \\ Universidade do Vale do Rio dos Sinos \\ doroteafk@unisinos.br \\ Ariadne Machado de Oliveira \\ Universidade do Vale do Rio dos Sinos \\ aryamani@hotmail.com
}

\section{Resumo}

Neste artigo, apresenta-se o resultado de uma investigação feita com professores da rede municipal de Novo Hamburgo-RS, quanto às crenças sobre o trabalho com gêneros do domínio do argumentar no ensino fundamental. Mostra-se também como os documentos oficiais se posicionam em relação à prática com argumentação e qual o espaço que os livros didáticos usados pelos professores investigados dão aos gêneros do agrupamento do argumentar. Os dados foram gerados a partir da gravação de reuniões de estudo das coordenadoras do projeto de pesquisa com professores e alunos bolsistas, de graduação e pós-graduação e fizeram-se entrevistas semiestruturadas com alguns professores antes e depois do trabalho que desenvolveram. Os resultados mostram que a pouca atenção dada à argumentação na escola básica se deve, em parte, à crença dos professores de que, para argumentar, os alunos precisam estar maduros. Além disso, o fato de os livros didáticos priorizarem o trabalho com gêneros de outros agrupamentos parece confirmar para o professor que, para argumentar, é necessário ter maturidade.

Palavras-chave: Argumentação, formação continuada, projeto didático de gênero, crenças.

\begin{abstract}
This article presents the results of an investigation carried out with teachers from municipal schools in Novo Hamburgo-RS, Brasil, concerning the beliefs that they have about working with genres of argumentative domain in the elementary school. The study also shows what
\end{abstract}


the official documents say about the practice of argumentation and the opportunities provided by the textbooks used by the investigated teachers to work with the genres of the argumentation group. The data analyzed resulted from the recordings of study meetings among the coordinators of the research project, the teachers and research assistant students from the under-graduate, as well as the graduate programs. Semi-structures interviews were also conducted with some of the teachers before and after the work they developed. The results show that the little attention given to argumentation in primary school is due in part to the fact that teachers believe students must be mature before they can argue. Besides that, the fact that textbooks prioritize genres of other kinds seems to confirm to the teacher that maturity is a requirement for argumentation.

Keywords: argumentation, continuing education, didactic project based on genres, beliefs.

\section{Introdução}

Trabalhar com argumentação não tem sido tarefa fácil para os professores de ensino médio. Para os professores de ensino infantil e fundamental, então, essa atividade chega a ser impensável. Nosso trabalho com professores de escola pública tem nos mostrado que essa resistência é sustentada por algumas crenças, que vamos discutir aqui. Neste trabalho, temos como objetivo, pois, investigar o que cinco professores pensam sobre o que é trabalhar com argumentação em sala de aula.

Os professores investigados integram um projeto maior, que tem apoio do Programa Observatório da Educação da Capes. A equipe é constituída por pesquisadoras do Programa de Pós-Graduação em Linguística Aplicada da Universidade do Vale do Rio dos Sinos (UNISINOS), além de alunos de graduação, mestrandos, doutorandos e professores da rede municipal de Novo Hamburgo-RS.

O grupo se reúne semanalmente e discute textos teóricos para fornecer um melhor embasamento para a elaboração e desenvolvimento de projetos a serem trabalhados com os alunos. Nessas reuniões, os participantes constroem conhecimento que será levado posteriormente a suas aulas. Com todos os professores da área de linguagens da rede é desenvolvida uma formação continuada usando metodologias de ensino a distância, com encontros presenciais 
mensais, momentos em que eles trazem suas dificuldades e apresentam os projetos que desenvolvem com os alunos. Ao longo do desenvolvimento do projeto, as pesquisadoras, numa releitura das sequências didáticas (DOLZ; SCHNEUWLY, 2011), desenvolveram uma metodologia de trabalho denominada Projetos Didáticos de Gênero - PDG (KERSCH; GUIMARÃES, 2012).

No final de 2012, na última reunião presencial do ano, os professores solicitaram que, no ano seguinte, fosse dada atenção aos gêneros do domínio do argumentar, porque, segundo eles, havia pouco material disponível para trabalhar a questão. Enfatizaram que tampouco os livros didáticos se ocupavam mais exaustivamente com gêneros desse domínio, o que acabava limitando também seu trabalho com esses gêneros.

Nesse cenário, pergunta-se: "quais são as crenças e práticas de professores quanto ao trabalho com gêneros do domínio do argumentar com alunos de ensino fundamental?". A partir desse questionamento, nosso objetivo é identificar as crenças dos professores participantes da pesquisa em relação ao trabalho com gêneros do domínio do argumentar e delinear as dificuldades com que se deparam quando decidem trabalhar a argumentação com seus alunos, bem como verificar se, no âmbito da formação continuada de que participam, os professores tiveram a oportunidade de ressignificar suas crenças.

$\mathrm{O}$ artigo acha-se dividido, além desta introdução, em quatro partes: inicia-se discutindo aspectos relevantes em relação à prática da argumentação e sobre como ela é vista nos livros didáticos usados pelos professores participantes da pesquisa e nos documentos oficiais, que orientam sua ação, para depois fazer uma breve discussão sobre o conceito de crenças. Em seguida, descreve-se a metodologia usada para a geração de dados. Na terceira parte, analisam-se e discutem-se os dados. Por fim, tecem-se algumas considerações finais e indicam-se outras possibilidades de estudo.

\section{Sobre argumentação}

Ao contrário do que se pensa normalmente, a argumentação é prática cotidiana, intrínseca à ação de linguagem. Para Golder e Coirier (1996), toda prática linguageira é argumentativa. Segundo os autores, 
não é possível produzir discurso sem intenção e sem uma estratégia argumentativa. É nesse discurso que o locutor transmite o seu sistema de valores e suas atitudes, e tenta persuadir, convencer o seu interlocutor de que suas ideias têm validade e são passíveis de consideração.

Identificada a necessidade dos professores de produzir objetos de ensino que enfocassem a argumentação, nas reuniões do grupo, buscou-se compreender como Bronckart (2012), Dolz e Schneuwly (2011) e Dolz, Gagon e Decânio (2011) caracterizam os gêneros do domínio do argumentar, os dois últimos com ênfase no ensino da argumentação.

A prática argumentativa, conforme Bronckart (2012, p. 26), implica "a existência de uma tese, supostamente admitida, a respeito de um dado tema. Sobre o pano de fundo dessa tese anterior, são então propostos dados novos, que são objeto de um processo de inferência, que orienta para uma conclusão ou nova tese". No meio desse trajeto, podem ocorrer intromissões discursivas como contra-argumentos, que têm como escopo corroborar a tese defendida, prevendo a contraposição do interlocutor. No fim da sequência argumentativa, o locutor reforça seu posicionamento inicial em uma fase de conclusão, que integra os efeitos do movimento de argumentos e contraargumentos expostos ao longo do discurso.

Nos estudos de Dolz (1993), a situação de produção tem grande relevância na sequência argumentativa. $\mathrm{O}$ momento em que ocorre essa atividade, o local geográfico e o lugar social definem tanto a estratégia a ser utilizada quanto o sucesso (ou insucesso) dessa estratégia. Explorar o espaço escolar como propulsor da atividade argumentativa é uma das discussões do autor. Ele defende que o ensino da argumentação deve ser feito desde os anos iniciais da vida escolar, "em razão de sua frequência nas interações sociais diárias (na família, na escola, no trabalho, etc)" (DOLZ, 1993) e também porque somos, a todo momento, produtores ou receptores de discursos argumentativos, tanto orais quanto escritos.

Nessa perspectiva, com a qual concordamos, é, pois, possível trabalhar com argumentação em todas as fases da vida escolar. Dolz e Schneuwly (2011) destinam, em seu livro "Gêneros orais e escritos na escola", um capítulo para relatar uma experiência de sala de aula, cujo objeto de ensino foi o gênero debate - enquadrado no domínio do 
argumentar. Os autores explicam que gêneros dessa ordem desempenham um papel importante na sociedade, uma vez que fazem parte da prática cotidiana de qualquer cidadão ativo. Estudar gêneros dessa natureza significa, portanto, desenvolver nos alunos capacidades para defender - oralmente ou por escrito - um ponto de vista, além de capacidades concernentes à própria prática comunicativa, como a de gestão da palavra, escuta do outro, intervenções no discurso. Outro ponto crucial a ser desenvolvido por meio do trabalho com argumentação em sala de aula é o olhar individual: o aluno será capaz de se situar, de tomar posição, de ponderar, de discernir e de ver a si, enfim, de construir a sua identidade.

O lugar social em que circula o gênero também foi trabalhado com o grupo de professores. Dolz, Gagnon e Decândio (2010, p. 83), fazendo referência a Chartrand (1995), mencionam que a argumentação desencadeia uma reestruturação das funções primeiras do processo de comunicação: "exprimir a si mesmo e interiorizar o outro, provocar uma impressão sobre o outro e transformar seu pensamento; descrever o mundo por meio do diálogo com o pensamento do outro". Assim, levar os alunos a criarem essa imagem sobre o outro, o que vai impactar as escolhas que terão de fazer para serem bem-sucedidos em sua interlocução, escolherem o suporte em que o gênero circula e, por fim, efetivamente se comunicarem, pode desencadear uma grande mudança na sala de aula, até mesmo explorando os seus limites.

\section{Sobre a argumentação nos documentos oficiais e nos livros didáticos}

Para ensinar argumentação na escola, o professor de língua portuguesa se apoia, frequentemente, como relatado por aqueles com quem trabalhamos, nos livros didáticos. Os professores de séries iniciais, entretanto, encontram maiores dificuldades quando buscam nesse material o suporte para a sua prática pedagógica. Livros aprovados e indicados pelo PNLD/MEC (Programa Nacional do Livro Didático) para as séries iniciais abordam os gêneros pertencentes ao domínio do argumentar de modo insuficiente, contribuindo, desse 
modo, para a sustentação de certas crenças, como "crianças não são capazes de argumentar" ou "o trabalho com argumentação nas séries iniciais não é adequado".

De acordo com o levantamento feito por Leal, Andrade e Brandão ${ }^{1}$, apenas 7,3\% do total de textos presentes em livros didáticos para o primeiro e segundo ciclos do Ensino Fundamental são do domínio do argumentar. A falta de abordagem de gêneros pertencentes ao domínio do argumentar ajuda a explicar a dificuldade que os professores têm em sala de aula (e que, às vezes, é a sua própria também, como verificamos em estudo que desenvolvemos (AUTOR, no prelo)). Muitas vezes, os professores, seja por orientação da escola, seja por falta de opção, se veem obrigados a aceitar o que o livro traz como ideal para aquela determinada série e, por essa razão, continuam alimentados pela crença de que o trabalho com a argumentação é inadequado para o seu grupo de alunos.

Do mesmo modo, analisando os livros didáticos ${ }^{2}$ que os professores participantes de nossa pesquisa dizem usar em suas escolas, verificamos que é muito expressiva a atenção dada ao trabalho com gêneros pertencentes ao domínio do narrar. Nos volumes destinados às séries iniciais do Ensino Fundamental, é possível perceber a presença de gêneros pertencentes a outros domínios, como reportagem, relato de memória, carta pessoal e cartão postal; entretanto, o domínio do argumentar aparece apenas uma vez nas séries iniciais, a partir de um gênero, cujas características estão predominantemente enquadradas no domínio do narrar: a crônica.

${ }^{1}$ Ver resultados detalhados desse levantamento em: http://alb.com.br/arquivomorto/edicoes_anteriores/anais15/alfabetica/LealTelmaFerraz3.htm

${ }^{2}$ Foram analisados três livros didáticos utilizados em escolas do município de Novo Hamburgo:

BORGATtO, A. M. T., BERTIN, T. C. H., MARCHEZI, V. L. C. Ápis: Língua Portuguesa. São Paulo: Ática, 1. Edição, 2011.

BRAGANÇA, A., CARPANEDA, I. Porta Aberta: Língua Portuguesa. São Paulo: FTD, 1. Edição, 2011.

CEREJA, W. R., MAGAlHÃES, T. C. Português Linguagens. Ensino Médio. São Paulo: Atual Editora, 8. Edição, 2012. 
Nos volumes das séries finais do Ensino Fundamental, encontramos também discrepâncias quanto ao espaço destinado aos diferentes agrupamentos de gêneros. Nos exemplares de $6^{\circ}$ e $7^{\circ}$ anos, ainda se encontram muitos gêneros do agrupamento do narrar, do expor e do relatar; ao passo que poucos, como se disse, visam ao trabalho com a argumentação. Os gêneros desse domínio só começam a ser propostos a partir do $8^{\circ}$ ano, porém ainda timidamente, e, no $9^{\circ}$ ano, aparecem artigos de opinião, debates, resenhas e as típicas propostas de redação escolar, as "dissertações".

A partir das coleções distribuídas aos alunos do Ensino Médio, tem-se a oportunidade de trabalhar de forma mais intensa com argumentação. $\mathrm{O}$ desequilíbrio do trabalho entre os diferentes eixos pode ser percebido na escolha e na abordagem dos diferentes gêneros; aparecem textos provenientes de jornais, revistas e páginas da internet, ora enquadrados no domínio do expor, ora no do argumentar. Em menor quantidade, os volumes contemplam gêneros como contos e crônicas, mas as atividades que acompanham tais textos se preocupam mais em explorar sua forma e não dão muita importância à singularidade e subjetividade que acompanham os gêneros pertencentes ao domínio do narrar.

Fica claro, pois, que o massivo trabalho com o domínio do narrar oferecido e fortemente recomendado pelos livros didáticos institui no imaginário do professor a ideia de que crianças não podem trabalhar suas habilidades argumentativas, já que, como mostra Souza (2005), o sumário do livro didático acaba sendo a lista de conteúdos a serem trabalhados pelo professor. Os autores dos livros didáticos partem, possivelmente, da premissa de que se deve trabalhar muito mais fortemente o imaginário das crianças, e as narrativas contribuiriam para isso.

Para os Parâmetros Curriculares Nacionais (PCN) (BRASIL, 1998, p. 26), ao trabalhar com argumentação, o professor deveria "privilegiar textos de gêneros que aparecem com maior frequência na realidade social e no universo escolar". A escolha de textos como editoriais, cartas argumentativas, cartas de solicitação, de reclamação, do leitor, debates regrados e diálogos argumentativos precisa ser adequada à idade e à série, para que o ensino se dê de modo significativo. 
Com a finalidade de desenvolver a capacidade crítica dos alunos, os PCN (BRASIL, 1998, p. 41) sugerem a discussão de aspectos polêmicos inerentes aos temas sociais. Esse documento defende, ainda, que tarefas como essa são "relevantes para o exercício da cidadania". Além disso, ao se exercitar o diálogo na explicitação, contraposição e argumentação, os alunos aprendem também a agir dentro do meio e desenvolvem "atitudes de confiança, de capacidade para interagir e de respeito ao outro".

Do mesmo modo, os Referenciais Curriculares do Rio Grande do Sul (RIO GRANDE DO SUL, 2009) também valorizam o trabalho com argumentação em sala de aula desde as séries iniciais. Em seu primeiro capítulo, os autores provocam aqueles que sustentam a ideia de que a argumentação é um conteúdo complicado para as crianças: "Também discordamos da visão de que, na $5^{\mathrm{a}}$ série, ainda não se consegue argumentar por escrito, devendo o trabalho, neste nível de ensino, concentrar-se em descrições e relatos, para somente no ensino médio serem trabalhadas as competências de argumentação." (RIO GRANDE DO SUL, 2009, p. 93). O que poderia ser feito, de acordo com os Referenciais, é a abordagem oral - quando as crianças não são alfabetizadas - e, no caso de crianças de séries iniciais, a escrita de textos com estruturas menos complexas - como, por exemplo, cartas simples em que seja discutido algum tema, ou mesmo, feito algum pedido.

O documento discute, ainda, a relevância do ensino da argumentação, reconhecendo que, "desde que começam a falar, as crianças realizam inferências e argumentam, entre tantas outras ações de linguagem que estão sempre imbricadas" (p. 93-94), ou seja, as crianças são capazes, sim, de agir como autoras e receptoras de discursos argumentativos.

Os documentos oficiais, portanto, estão preocupados em formar cidadãos capazes de se posicionar, colocar, de forma respeitosa, o seu ponto de vista, dar respostas consistentes. Respeitar a opinião alheia e saber ouvir e considerar perspectivas diferentes sem se sentirem ameaçados também é defendido por esses documentos e são questões que, a nosso ver, acabam sendo esquecidas na escola contemporânea. O aluno que, desde seus primeiros anos escolares, estiver envolvido no trabalho com a argumentação, poderá ser mais capaz de ouvir e respeitar a visão do outro, de argumentar e contra- 
argumentar. O desenvolvimento dessas habilidades pode levá-lo a viver de forma harmoniosa em sociedade, com tolerância e de forma crítica, para não aceitar injustiças e incoerências que acontecem diariamente em seu meio

É preciso, pois, que a escola reconheça essas habilidades prévias dos alunos. Sem esse ponto de partida, o professor pode chegar a não explorar habilidades que o aluno já leva à escola, e, consequentemente, pode acabar não aproveitando o espaço escolar como um contexto propício ao debate crítico, ao exercício contínuo de aceitação, de contornar a conversação, com o fim de estabelecer um contrato discursivo, contrapondo posições e conceitos. O ideal seria que a sala de aula fosse usada como palco de práticas resultantes da disposição de ouvir o outro, em que é considerada a opinião do outro e onde é possível colocar a sua própria visão, em uma situação dialógica harmoniosa e, portanto, exitosa. Isso é o que esperam os documentos oficiais.

\section{Breve discussão sobre crenças}

Ainda que, segundo Barcelos (2004), a pesquisa sobre crenças no âmbito da Linguística Aplicada no Brasil tenha iniciado nos anos 90 do século passado, é bastante expressiva, de lá para cá, a produção de dissertações de mestrado, teses de doutorado, livros e artigos científicos em periódicos e apresentações em eventos que abordam a temática das crenças, de modo especial as relacionadas ao ensino de língua estrangeira (BARCELOS, 2004; 2007; SILVA, 2007).

Trata-se de um conceito complexo, o que faz com que sejam usados vários termos e definições para referir-se às crenças relacionadas ao ensino e aprendizagem de línguas. Barcelos (2004) faz uma sistematização desses termos e conceitos (representações, crenças, cultura de aprender, concepções, entre outros) $)^{3}$ e observa que essa diversidade de acepções nos leva a perceber que

todas as definições enfatizam que as crenças se referem à natureza da linguagem e ao ensino/aprendizagem de línguas

${ }^{3}$ Cf. Barcelos, 2004, p. 130-132. 
(...) do que é linguagem, do que é aprendizagem de línguas e sobre aspectos pertinentes à linguagem e à aprendizagem (...) as outras definições enfatizam mais o aspecto cultural e a natureza social de crenças, colocando-as como ferramentas que ajudam os alunos a interpretar suas experiências. (BARCELOS, 2004, p. 132)

Ainda que a maioria dos trabalhos sobre crenças esteja focada nos alunos ${ }^{4}$, neste artigo nos focamos no professor. Quando falamos de crenças aqui, estamos falando de (pré)concepções, ideias e opiniões que professores têm sobre o que seja ensinar e aprender línguas. No nosso caso, as concepções de professoras de língua materna sobre o que e quando gêneros do domínio do argumentar podem ser ensinados aos alunos.

Crenças não surgem no vácuo; é na interação, com os outros, por meio da linguagem, que elas emergem. São, pois, construídas social e historicamente, ou, como afirma Barcelos (2001, p. 73), "as crenças são pessoais, contextuais, episódicas e têm origem nas nossas experiências, na cultura e no folclore. As crenças também podem ser internamente inconsistentes e contraditórias".

Elas são dinâmicas e situadas contextualmente. Elas direcionam o nosso agir. Por essa natureza dinâmica das crenças, elas podem mudar se nos é dada a oportunidade de ressignificá-las. Como elas condicionam o nosso agir, se o professor é levado a refletir sobre a sua prática, ele pode passar a compreender o que faz de outra forma, desconstruir suas crenças e, consequentemente, mudar sua prática. E, nesse processo, a formação continuada cooperativa, como a compreendemos, desempenha papel fundamental.

\section{Metodologia}

A pesquisa é qualitativa e interpretativista. $\mathrm{O}$ corpus gerado inclui transcrições de áudio de duas das reuniões semanais entre esses

\footnotetext{
${ }^{4}$ Em função dos objetivos deste artigo, não vamos nos estender nessa questão, mas para conhecer os estudos realizados sobre crenças no Brasil, vejam-se os trabalhos de Barcelos $(2001 ; 2004 ; 2006,2007)$
} 
professores e os outros membros do grupo quando se discutiam os gêneros do agrupamento do argumentar. Também se fizeram entrevistas individuais com cinco professores da rede municipal de Novo Hamburgo-RS, antes e depois de elaborarem PDGs com gêneros do domínio do argumentar. Nas reuniões, habitualmente, cada um contribui, a sua maneira, para a construção colaborativa dos conhecimentos acerca do trabalho com gêneros do discurso, das práticas de letramento e para a construção de objetos de ensino, com a metodologia denominada no grupo de projeto didático de gênero PDG (KERSCH; GUIMARÃES, 2012), uma releitura da sequência didática (SCHNEWLY; DOLZ, 2011), com apoio nos projetos de letramento (KLEIMAN, 2000).

As reuniões, semanais, são momentos em que reflexões acadêmicas e prática pedagógica se aproximam. Nesses encontros, o grupo realiza leituras e discussões de textos teóricos e toma parte diretamente da produção acadêmica, como em apresentações de trabalhos em congressos e na escrita de artigos científicos para integrar os livros produzidos pelo grupo. De forma cooperativa ${ }^{5}$, o grupo também se envolve na elaboração de PDGs: professores da rede municipal e acadêmicos tornam realidade o produto das reflexões feitas pelo grupo na aplicação desses projetos com seus alunos. É através desses projetos que as considerações feitas semanalmente encontram ressonância na sala de aula.

Existe a preocupação de documentar não só as reuniões semanais do grupo, mas também de acompanhar o projeto didático de gênero tomando vida no 'chão' escolar. Parte do processo reflexivo no grupo origina-se dos registros das reuniões, em forma de diário de campo, das entrevistas feitas com os professores da rede e da aplicação dos projetos didáticos de gênero nas escolas envolvidas no projeto, gravadas em áudio e depois transcritas.

Compõem o conjunto de dados desta pesquisa: a gravação e transcrição de duas reuniões em que se discutia a elaboração de projetos didáticos de gênero (PDG); notas de campo do registro das reuniões, em que se verificou a dificuldade com que os professores lidavam com a argumentação; e entrevistas a cinco professores que participaram das reuniões e elaboraram e desenvolveram PDGs. As

${ }^{5}$ Cfe. Carnin (2015). 
entrevistas, gravadas em áudio e depois transcritas, foram realizadas na universidade, enquanto os projetos estavam sendo elaborados. Perguntas como "O que é argumentar? Para que serve? Em que situações argumentamos? Há uma fase/série que seja a ideal para o trabalho com esse domínio? Quais são os materiais usados como suporte? Qual a relevância do ensino de argumentação no Ensino Fundamental?" serviram para reunir o que o professor pensa e faz em sala de aula quando o assunto é a argumentação. Após o desenvolvimento dos projetos com os alunos, os professores foram novamente ouvidos, de modo a verificar se suas crenças foram ressignificadas.

As categorias de análise escolhidas permitem seguir um continuum em que as crenças podem ser ressignificadas: o conhecimento tácito que orienta o agir $\rightarrow$ a reflexão sobre as razões desse agir $\rightarrow$ novo agir motivado pela reflexão $\rightarrow$ crença desconstruída/ressignificada.

Os nomes dos participantes, a fim de preservar sua identidade, são fictícios. Todos têm diferentes experiências, ainda que todos tenham uma carga horária de trabalho semanal de 40 horas. Quatro deles são bolsistas Capes, do Programa Observatório da Educação. Cristina tem 30 anos, trabalha há 9 anos com as séries finais do Ensino Fundamental e com turmas de Ensino Médio. Daniela há 30 anos leciona nas séries finais do Ensino Fundamental, é a única do grupo investigado que não é bolsista, mas participava regularmente da formação continuada, comparecendo a todas as reuniões presenciais. Luísa tem 35 anos e é formada há 6. Trabalha com as séries iniciais e finais do Ensino Fundamental. Marisa tem 45 anos, formada há 9 anos e leciona há 14 anos. No momento da pesquisa, trabalhava com as séries iniciais do Ensino Fundamental. Por fim, Marcos tem 46 anos, leciona há 13 anos nas séries finais do Ensino Fundamental e Ensino Médio. Está afastado do cargo de professor e trabalha na Secretaria de Educação do município. Todos eles têm formação em Letras Português. Duas delas são habilitadas em Inglês e uma, em espanhol. 


\section{Análise e discussão dos dados}

Os professores com que vimos trabalhando desde 2011, no âmbito da pesquisa antes mencionada, nos ajudaram a construir uma via que liga a academia à escola, diálogo tão necessário e tão pouco frequente. Quando eles trouxeram para a nossa comunidade de indagação (KERSCH; GUIMARÃES, 2012) a demanda por orientações sobre como trabalhar com argumentação, sentimo-nos desafiadas, sabíamos que teríamos de desconstruir e ajudar a ressignificar crenças, abalar certezas, construir uma base a partir da qual eles pudessem, depois, trabalhar com liberdade e autonomia.

Influenciados pela visão dos autores dos materiais didáticos utilizados como suporte, professores parecem estruturar seus currículos a partir do que o livro traça como ideal. Entre os participantes de nossa pesquisa, os livros ainda são tidos como o principal material de fonte para elaboração das aulas, e são eles que ainda ditam a prática pedagógica desses professores. Parece-nos que os poucos textos do domínio do argumentar presentes nesse material, como dissemos acima, levam o professor a pensar que os alunos não serão capazes de ler, entender ou produzir um texto argumentativo (talvez nem ele a preparar uma aula em que, a partir do conhecimento do aluno, seja considerada a possibilidade de fazer uma proposta vinculada à prática social e que fuja da tão propalada redação escolar). Tentamos ver, em nossos dados, um processo por meio do qual as crenças poderiam ser descontruídas, e são as categorias escolhidas que nos levam à identificação desse processo.

\section{1 “Crianças não têm condições de argumentar”: crença que adia o trabalho com a argumentação}

A fala de Cristina, professora de uma turma de $4^{\circ}$ ano do Ensino Fundamental em uma das entrevistas feitas, ilustra bem a suposta incapacidade dos alunos em argumentar: "Os alunos têm condições de argumentar? Acho que não". Para ela, argumentar é difícil. Perguntamo-no: difícil para quem? Para os alunos ou para o professor? Talvez Cristina esteja se referindo à argumentação clássica, de tradição greco-latina, um gênero tradicionalmente escolarizado (e que vai gerar uma parente distante, a redação escolar), que, ainda em 
níveis avançados de escolaridade, apresenta dificuldades para os alunos.

A concepção de que somente alunos mais maduros estariam aptos para produzir textos argumentativos também transparece na fala de Daniela:

tô convencida que não é pra eles ainda. Tem que ter maturidade intelectual pra ti conseguir produzir. (Daniela, professora cursista ao falar, em entrevista, de seu trabalho com artigo de opinião no $7^{\circ}$ Ano).

Posicionamentos como os de Daniela e de Cristina são motivados pela crença de que existe idade para se aprender a argumentar, de que as práticas de linguagem que envolvem a argumentação só podem ser exercidas por alunos mais maduros, ou seja, apenas nas séries finais do ensino fundamental ou no ensino médio os alunos estariam aptos a isso.

O trabalho de Abchi, Dolz e Borzone (2012) mostra que, por meio de um trabalho sistemático, é possível desenvolver as capacidades de linguagem de alunos, mesmo que estejam ainda nos anos iniciais. Os autores acompanharam o desenvolvimento de sequências didáticas com alunos argentinos de terceiro ano, na elaboração de cartas de solicitação ao diretor do zoológico para a realização de uma visita, em que tinham de apresentar justificativas para tal visita. Ainda que as atividades desenvolvidas pelas professoras nas oficinas das sequências didáticas tivessem sido gerais e não explicitamente aplicadas ao gênero carta de solicitação, os resultados foram significativos na produção final. Provavelmente, se tivessem trabalhado com formulação de argumentos que os alunos poderiam usar para justificar seus pedidos e que poderiam ajudar a melhorar sua produção, os resultados poderiam ter sido ainda melhores.

Para os autores, os gêneros do agrupamento do argumentar requerem um ensino específico que leve em conta tanto os aspectos comunicativos como aqueles ligados à estrutura, organização das produções e aos mecanismos de textualização. Os autores lembram que constatações semelhantes se puderam fazer na análise de trabalho de professores da Suíça francófona com sequências didáticas, em que também se observou que eles nem sempre trabalharam as dificuldades 
dos alunos apresentadas na produção inicial. Para nós, no âmbito do trabalho com PDG, a exemplo da sequência didática, é fundamental entender a produção inicial como o diagnóstico para o desenvolvimento das atividades restantes. Ainda que os alunos tenham um conhecimento prévio acerca de uma grande quantidade de gêneros, a produção inicial mostra ao professor o que ele precisa ensinar àqueles alunos, uma vez que cada ensino é situado sociohistoricamente.

Entendemos também que a escola, a principal agência de letramento, é também o principal lugar em que se trabalha com a linguagem, é dela o papel de ensinar, cabe principalmente às aulas de língua portuguesa ensinar a ler e escrever os mais variados gêneros. Marques (2014) mostra como, por meio de um trabalho sistemático, com a oferta de oficinas que efetivamente trabalhem as dificuldades dos alunos manifestadas na produção inicial, é possível desenvolver as capacidades de linguagem dos alunos. Exatamente o que Abchi, Dolz e Borzone (2012) sentiram falta nos resultados dos alunos argentinos, fica evidente no trabalho de Marques (2014), mas a autora atribui o sucesso do trabalho dos alunos que acompanhou a

uma proposta metodológica que oriente o professor a desenvolver um projeto que tenha como meta ensinar $e$ vincular o gênero textual a uma prática social, assim como explorar e ensinar a usar os recursos linguísticos para a formalização do texto, promovendo, dessa forma, um espaço para o aluno se apropriar de uma prática de linguagem e acionar suas capacidades de linguagem. (MARQUES, 2014, p. 130)

Ou seja, se 'o que ensinar' (e nisso se inclui a argumentação), estiver ligado a uma necessidade dos alunos, eles aprenderão, ainda que possa parecer difícil, tanto para o professor quanto para eles. Se professor e alunos estiverem engajados num projeto que faça sentido para ambos, até o que parece "não ser ainda para eles", como afirma Daniela, poderá revelar grandes surpresas. A crença de que somente alunos mais maduros poderiam argumentar pode ser ressignificada, desde que seja dada a oportunidade ao professor de refletir sobre sua 
prática e, embasado teoricamente, analisando os resultados do projeto desenvolvido, desconstruí-la.

\section{2 "Às vezes subestimamos a capacidade argumentativa de nossos alunos": a formação continuada e a desconstrução de crenças}

Muitas crenças são alimentadas no nosso dia a dia. Assim também na vida do professor, que gosta de ter o controle de sua aula, que precisa 'vencer os conteúdos' previamente determinados (antes mesmo de saber quem serão seus alunos, quais dificuldades terão). Como a lista de conteúdos parece ser seu fim primeiro, acaba não ouvindo muito o aluno, repetindo as mesmas aulas para diferentes turmas, em diferentes escolas (até porque precisa se desdobrar para dar conta de preparar aulas a serem ministradas em suas 40, e às vezes 60 , horas semanais). Pouco tempo sobra, pois, para pensar, planejar, ler ${ }^{6}$. Poucos espaços há na escola para o professor discutir assuntos relacionados à sua atuação acadêmica. As reuniões pedagógicas acabam sendo apenas informativas. Não conhecendo, pois, de fato, seus alunos, o professor acaba por subestimar sua capacidade, como afirma Marisa, durante a conversa que tivemos com ela após ela ter trabalhado com argumentação. A crença muitas vezes se forma no senso comum e, no caso dos nossos professores, ela é reforçada pelos materiais que orientam sua ação (livro didático, lista anual de conteúdos da escola). Nada como o encorajamento para tentar fazer diferente para a desconstrução de crenças que parecem solidificadas.

Em nossa comunidade de indagação, sempre procuramos criar um espaço propício para debater, para tirar dúvidas, criar, enfim, o espaço que o professor normalmente não tem no seu dia a dia. Esse espaço foi construído com os professores na formação continuada prevista no projeto que ajudamos a desenvolver. Sabemos que desconstruir crenças, muitas vezes cristalizadas, requer trabalho de reflexão e discussão. Marisa mostra isso em sua fala:

\footnotetext{
${ }^{6}$ Parece-nos que a vida de Claudete Borges, em "Um dia na vida de um professor", apresentada em Carta Capital (http://www.cartacapital.com.br/revista/749), é realidade na vida de grande parte dos professores de escolas públicas brasileiras.
} 
Precisava me desconstruir de alguns conceitos e também preconceitos em relação ao ensino da Língua Portuguesa (...) (Marisa, na entrevista em que fala de sua experiência com o trabalho com PDGs)

A visão que se tinha sobre o trabalho com a argumentação no ensino fundamental começa a mudar para os professores que ousaram experimentar, tentar o diferente. Nos encontros semanais, foram feitos os planejamentos, a elaboração dos PDGs, e coube aos professores o desenvolvimento dos projetos com os alunos. Dar voz ao professor e, junto com ele, quebrar preconceitos, faz com que também ele faça isso com seus alunos, transformando a sala de aula num laboratório onde se experimentam alternativas. $\mathrm{Na}$ formação continuada como a entendemos, o professor tinha de experimentar essa tomada da fala nos encontros semanais. No trabalho direto com eles, foi possível saber quantas dúvidas também eles tinham a respeito de gêneros do domínio do argumentar, como pode ser identificado em nossas notas de campo. Essas dúvidas talvez fizessem com que não considerassem o conhecimento que o aluno traz de casa, subestimando-o, como constata Marisa, em entrevista após ter trabalhado argumentação com seus alunos:

Isso demonstra que, muitas vezes, nós, professores, subestimamos a capacidade argumentativa e questionadora que possuem nossos alunos (...). (Marisa, em entrevista, ao falar como a formação continuada mudou seus (pre)conceitos)

Trabalhar argumentação com crianças, como afirma Cotteron (1995), pode ser perigoso, porque, ao dar a elas a chance de se manifestarem, é como se estivéssemos lhes dando um cartucho de dinamite que pode jogar nossa importância no ar, fazendo estremecer nossa imagem de quem ensina, de pai, de adulto (p. 80). Em Autor (2014), demonstramos como os professores tinham eles próprios dificuldades em identificar gêneros essencialmente do agrupamento do argumentar, em aceitar que uma crônica, ainda que possa apresentar sequências argumentativas, não é um gênero que integra esse agrupamento. Também, como mencionamos antes, os professores entrevistados, mencionaram que o livro didático é sua principal fonte 
de consulta e estudo para planejamento de suas aulas. Assim, o trabalho com gêneros desse domínio acaba sendo protelado.

Cotteron (1995, p. 80) crê que, ao entrarmos no campo da argumentação, estamos tratando de nossas crenças e valores, o que nos afeta intelectual, afetiva e psicologicamente, até porque nossa relação com a argumentação é, muitas vezes, conflitiva, uma vez que está marcada

por las representaciones que tenemos de nuestra capacidad para argumentar, de nuestros fracasos o éxitos en este ámbito, de nuestro temor o nuestra impresión de estar manipulados en nuestra vida privada o pública por hábiles dialécticos, de nuestro escepticismo sobre la realidad de una argumentación concebida como una negogiación entre iguales, cuando, demasiado a menudo, el objetivo pretendido del que argumenta es reducir al outro al silencio y a la submisón. (COTTERON, 1995, p. 80)

Abrir espaço para a argumentação na sala de aula, seja oralmente ou por escrito, é abrir-se ao diálogo, à negociação. Os recursos linguísticos para construir argumentos precisam ser ensinados, assim como o respeito à opinião do outro, e isso pode ser ensinado precocemente, com o que concordamos com Dolz (1993) ${ }^{7}$. Entre os professores com que trabalhamos na formação continuada, a posição de que é possível, sim, trabalhar com argumentação em qualquer série escolar é marcada na fala de Marcos:

Mas é uma coisa que eles fazem muito. Argumentar é bem a fase deles. (Marcos, professor de $9^{\circ}$ ano, ao, em entrevista, falar sobre argumentação no ensino fundamental.)

Marcos, diferentemente da maioria de seus/suas colegas, vê a argumentação como própria dos alunos; portanto, uma importante possibilidade para desenvolver seu letramento e munir os alunos das ferramentas necessárias para tal: ensinar a construir argumentos, a

${ }^{7}$ Nós o testamos em nosso grupo, em que uma professora trabalhou o debate regrado com uma turma de $3^{\mathrm{a}}$ série, cuja produção inicial e final foram filmados. O relato dessa experiência gerou um artigo que compõe o segundo livro do nosso projeto (CORREA, 2014). 
apropriar-se dos recursos linguísticos adequados, a negociar uma posição, a respeitar a opinião do outro, a aprender a ouvir. Luísa se alinha a essa concepção:

Eu acho que esse domínio pode ser usado em qualquer série, até na Educação Infantil, né? Eu acho que, às vezes, a gente facilita as coisas, que a gente acha que as crianças não têm capacidade, mas é só o modo de trazer, porque eles tão aí aprendendo coisas... que são muito além da nossa capacidade, eles aprendem antes, então... Eu acho que tu tem que ter um por que, um pra quê. (Luísa, ao em entrevista falar sobre a possibilidade de trabalhar com argumentação no ensino fundamental)

Luísa é da opinião de que o aluno tem um conhecimento prévio (eles tão aí aprendendo coisas (...) eles aprendem antes) que pode se explorado. Tudo depende de que e de como o fazemos. E o projeto didático de gênero se presta bem a isso.

\section{3 "Mas é só o modo de trazer": o projeto didático de gênero como potencializador das atividades com linguagem}

Se vimos afirmando que é possível trabalhar com argumentação no ensino fundamental, é porque cremos que podemos aproveitar a capacidade de convencer que os alunos já trazem consigo da sua vida cotidiana para, na leitura ou escuta de textos, atentar para as características dos textos; comparar e contrastar situações de argumentação; elaborar diferentes tipos de argumentos; recomendar ou desaconselhar um livro ou filme; usar diferentes recursos linguísticos para elaborar argumentos; negociar com o interlocutor (ou o debatedor). Em síntese, 'é só o modo de trazer', como afirma Luísa. Mas chegar a essa concepção é um processo, e o professor precisa ser encorajado/subsidiado para tal.

O projeto didático de gênero, com as experiências que temos tido com os professores que acompanhamos, tem se mostrado uma metodologia bastante eficaz, "um modo de trazer" que tem trazido resultados muito bons ${ }^{8}$. Partindo de uma demanda dos alunos e

\footnotetext{
${ }^{8}$ Ver, por exemplo, Marques (2014b), no prelo.
} 
vinculando o projeto à prática social, para se chegar à produção do gênero, discute-se com os alunos a situação/contexto, parte-se para a produção inicial, para fazer um diagnóstico do que os alunos já sabem sobre o gênero, quais suas dificuldades linguísticas, o que será trabalhado nas oficinas, para, então, chegar à produção final. Nesse momento, é construída uma grade de avaliação junto com os alunos, e eles são os primeiros leitores críticos de seu próprio texto. Com base nessa grade, o professor faz, então, a leitura do texto, indicando melhorias, e conduz a reescrita. Pronto o texto, é hora de ele cumprir sua função, fazendo-o circular no espaço em que deve circular (ou seja, volta-se à prática social). A figura 1 ilustra os passos do PDG.

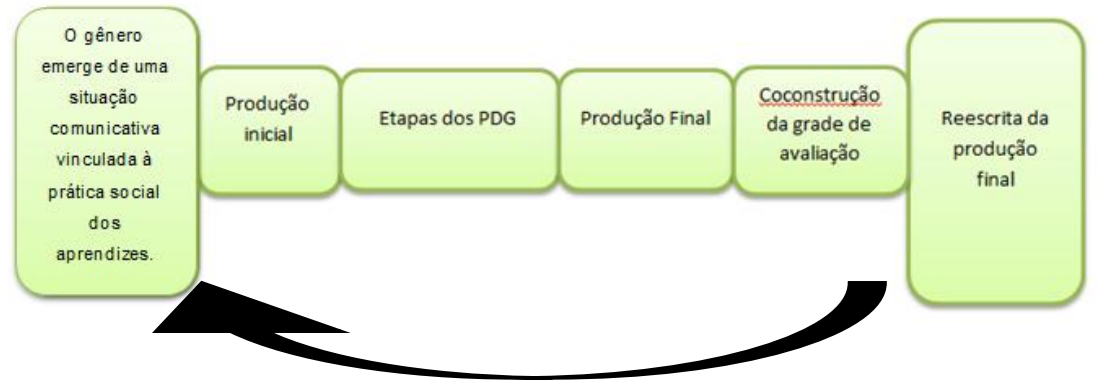

Figura 1 - Passos do Projeto Didático de Gênero (Marques, 2014, p. 59)

Como se pode observar, o aluno tem protagonismo no PDG, tendo participação ativa ao longo de todo o processo de construção. A mudança de perspectiva - escrever para agir no mundo e não para receber nota - aumenta a responsabilidade do aluno e compromete-o com o seu dizer. E é nesse papel ativo do aluno que reside o sucesso que temos alcançado, inclusive com multirrepetentes, que estão desacreditados por si mesmos, pela família e pela escola (MARQUES, 2014a).

Os bons resultados de alguns professores geraram mudança de atitudes, ressignificação de crenças. Entretanto, embora tenha havido uma considerável mudança na visão de alguns professores, outros se demonstraram, ainda, apegados à antiga forma de olhar para a argumentação - aquela produzida apenas para o professor corrigir, sem vinculação à prática social, e acharam melhor trabalhar gêneros de outros domínios (do narrar e do instruir, por exemplo), o que 
respeitamos, uma vez que o professor conhece os alunos melhor que nós. Interessa que transformações de cunho didático e pedagógico se apresentaram como principal ganho das reuniões e das discussões feitas na comunidade de indagação que ajudamos a coordenar.

A nova postura dos professores investigados na forma de ver a argumentação reorganizou também o planejamento desses professores, que, agora, já não concebem a ideia de não desenvolver projetos que envolvam a argumentação 9 . Toda a reflexão, antes e após o trabalho com gêneros do domínio do argumentar, portanto, não só oportunizou um olhar sobre o currículo, para pensar em mudá-lo, como deu oportunidade de rever as certezas, as posturas diante do que é trabalhar com linguagem na aula de língua materna, o que, inevitavelmente, mexe com a visão de mundo.

Ou seja, a partir das categorias de análise escolhidas a partir dos dados de que dispúnhamos, podemos pensar num processo para ressignificação de crenças: partir do conhecimento tácito originado, muitas vezes, no senso comum; refletir sobre a prática decorrente desse conjunto de crenças e verificar em que medida ela nos traz os resultados esperados, identificando as razões para os (pré)conceitos; repensar o agir, avaliando os novos resultados. Essa sequência, experienciada na formação continuada que ajudamos a promover, levou à ressignificação de crenças em relação ao que seja trabalhar com argumentação com alunos, ainda que em idade precoce.

\section{Considerações finais}

Os documentos oficiais defendem que, a partir da prática do argumentar na sala de aula, se desenvolvem atitudes de confiança, de interação e de respeito ao próximo, ou seja, saber argumentar solidifica princípios de cidadania. Entretanto, existe ainda a crença de que as crianças são muito pequenas para argumentar e falta suporte teórico ao professor, sobretudo do livro didático - sua principal fonte de consulta, o qual pouco explora gêneros pertencentes a esse domínio como mostramos neste texto.

9 Em nossas notas de campo, observamos o registro de que uma das professoras menciona que não sabe mais trabalhar sem ser por PDGs. 
Cria-se, pois, nos professores, um (pré)conceito que faz com que o trabalho com gêneros desse domínio seja adiado para o final das séries finais do ensino fundamental, ou para o ensino médio. A partir da demanda trazida pelos professores investigados de que o material existente era insuficiente, passou-se a estudar com eles alternativas, partindo do que é argumentação, quais as características dos gêneros do domínio do argumentar, para se chegar à criação de projetos didáticos de gênero que envolviam gêneros desse domínio. Em alguns professores, a resistência inicial deu lugar à ousadia, com a proposição de PDGs que foram desenvolvidos com os alunos. Os textos produzidos mereceriam um olhar para verificar de que estratégias os alunos se valeram para tentar convencer seu interlocutor.

O trabalho cooperativo mais uma vez nos mostrou a necessidade de que sejam criados espaços para o professor discutir suas dificuldades, suas angústias, ajudando-o a se tornar crítico sobre a sua prática, e ousado a ponto de não aceitar ideias cristalizadas, como a de que crianças são incapazes de argumentar.

Tentar fazer um trabalho diferenciado, que saia do formato tradicional de apenas 'fazer redações' para o professor corrigir e dar nota, ainda é um grande desafio para a escola básica. Organizar o currículo dos diferentes anos de modo que o gênero seja o catalizador das atividades é outro desafio, no qual estamos trabalhando com nosso grupo de trabalho, cujos resultados serão divulgados mais adiante.

As reflexões produzidas trouxeram, para esses professores, mudanças no modo de olhar para o trabalho com argumentação em sala de aula. A consideração por esse trabalho, antes praticamente inexistente, é parte do olhar constante desses professores, que mostraram, após os seus projetos, a possibilidade de êxito, independentemente do nível de ensino em que o trabalho com argumentação esteja envolvido. A desconstrução de crenças se dá, pois num continuum em que o conhecimento acadêmico dialoga com a prática, criando uma via de mão dupla, que liga a universidade à escola e vice-versa. 


\section{Referências}

ABCHI, Verónica S.; DOLZ, Joaquim; BORZONE, Ana M. Escribir textos argumentativos desde el inicio de la escolaridad. Un análisis de textos producidos a partir de una secuencia didáctica. Trabalhos em Linguística Aplicada, Campinas, v. 51, n. 2, Dez. 2012. Disponível em: <http://www.scielo.br/scielo.php?script=sci_arttext\&pid=S0103$18132012000200008 \& \operatorname{lng}=\mathrm{en} \& \mathrm{nrm}=\mathrm{iso}>$. Acesso em 15 Set. 2014.

BAKHTIN, Mikhail M. Estética da criação verbal. Trad.do russo de Paulo Bezerra. São Paulo: Martins Fontes, 2003. (Original russo, 1979).

BARCELOS, Ana M. F. Metodologia de pesquisa das crenças sobre aprendizagem de línguas: estado da arte. RBLA, v.1, n .1, p. 71-92, 2001

. Crenças sobre aprendizagem de línguas, Lingüística Aplicada e ensino de línguas; Linguagem \& Ensino, Pelotas, v. 7, n. 1, p. 123-156, jan./jul. 2004

- Cognição de professores e alunos: tendências recentes na pesquisa de crenças sobre ensino e aprendizagem de línguas. In: BARCELOS, Ana M. F.; VIEIRA-ABRAHÃO, Maria H.. (Orgs). Crenças e ensino de línguas: foco no professor, no aluno e na formação de professores. Campinas: Pontes, 2006. p. 15-41.

- Reflexões acerca da mudança de crenças sobre ensino e aprendizagem de línguas. RBLA. v. 7, n. 2, p. 109-138, 2007.

BRASIL. Parâmetros Curriculares Nacionais. Primeiro e segundo ciclos do ensino fundamental: língua estrangeira. Brasília: MEC/SEF, 1998.

BRASIL. Parâmetros Curriculares Nacionais. Terceiro e quarto ciclos do ensino fundamental: língua portuguesa. Brasília: MEC/SEF, 1998. 
“Argumentar é bem a fase deles"...

BRONCKART, Jean P. Atividade de linguagem, textos e discursos. Por um interacionismo sociodiscursivo. 2 ed. São Paulo: EDUC, 2012.

CARNIN, Anderson. Na escrita do professor um percurso possível para a análise do (seu) desenvolvimento profissional. Tese (Doutorado em Linguística Aplicada) - Universidade do Vale do Rio dos Sinos, São Leopoldo, 2015.

CORREA, Jane E. Debate regrado- possibilidade de trabalho com um gênero do domínio do argumentar em uma turma de $3^{\circ}$ ano do ensino fundamental. In: GUIMARÃES, Ana M. M.; KERSCH, Dorotea F. (Org.). Caminhos da construção: projetos didáticos de gênero na sala de aula de língua portuguesa 2. Campinas: Mercado de Letras, 2014.

COTTERON, J. Secuencias didácticas para enseñar a argumentar en la escuela primaria? Comunicacion, Lenguaje y Educación, v. 25, p. 7994, 1995.

DOLZ, Joaquim. Pour un enseignement precoce de l'argumentation. Journal de l'Enseignement Primaire, v. 43, n. 18/21. p. 18-21, 1993.

DOLZ, Joaquim; GAGNON, Roxane; DECÂNDIO, Fabrício. Produção escrita e dificuldades de aprendizagem. Adaptação Joaquim Dolz, Fabrício Decândio e Anna Rachel Machado. Campinas, SP: Mercado de Letras, 2010.

DOLZ, Joaquim; SCHNEUWLY, B. Gêneros orais e escritos na escola. Tradução e organização Roxane Rojo e Glaís Sales Cordeiro. 3 ed. Campinas: Mercado das Letras, 2011.

GOLDER, Caroline; COIRIER, Pierre. The production and recognition of typologial argumentative text markers. Argumentation, v. 10, n. 2, p. 271-28, 1996.

GUIMARÃES, Ana M. M.; KERSCH, Dorotea F. (Org.). Caminhos da construção: projetos didáticos de gênero na sala de aula de língua portuguesa. Campinas: Mercado de Letras, 2012. 
KERSCH, Dorotea F. GUIMARÃES, Ana M. M. A construção de projetos didáticos de leitura e escrita como resultado de uma proposta de formação continuada cooperativa. Revista Brasileira de Linguística Aplicada, v. 12, p. 533-556, 2012

KLEIMAN, Angela B. Apresentação. In: DIONISIO, Angela et al. (Org.). Gêneros textuais e ensino. Rio de Janeiro: Lucerna, 2000.

MARQUES, Renata G. Projeto didático de gênero como possibilidade para o ensino da língua materna e o desenvolvimento das capacidades de linguagem de alunos multirrepetentes, 2014. Dissertação (Mestrado em Linguística Aplicada) - Universidade do Vale do Rio dos Sinos, São Leopoldo, 2014.

MARQUES, Renata G. Projeto didático de gênero "adolescência, uma fase de risos e riscos" e seus efeitos fora dos muros da escolar. In: GUIMARÃES, Ana M. M.; KERSCH, Dorotea. F. (Org.). Caminhos da construção: projetos didáticos de gênero na sala de aula de língua portuguesa 2. Campinas: Mercado de Letras (2014).

PETRONI, Maria R. Construção do objeto discutível: argumentação e interação. Polifonia, n. 10, p. 113-133, 2005.

RIO GRANDE DO SUL. Referencial Curricular. Lições do Rio Grande. Linguagens, Códigos e suas Tecnologias. Volume 1. Secretaria da Educação do Rio Grande do Sul, 2009.

SILVA, Kleber A. Crenças sobre o ensino e aprendizagem de línguas na Lingüística aplicada: um panorama histórico dos estudos realizados no contexto brasileiro. Linguagem \& Ensino, v.10, n.1, p.235-271, jan./jun.2007.

SOUZA, Clara M. A recepção do livro didático de português e o processo de construção da competência leitora por alunos do ensino fundamental. 2014. Tese (Doutorado em Programa de Pós-Graduação em Estudos Lingüísticos) - Universidade Federal de Minas Gerais. 
“Argumentar é bem a fase deles"...

Submetido em: 19/09/2014 Aceito em: 30/04/2015

Title: "Arguing is the stage they're going through now": teachers' beliefs regarding argumentation in the classroom 